Predicting Corporate Failure: Empirical Evidence for the UK

by

\author{
Evridiki Neophytou \\ University of Southampton \\ Andreas Charitou \\ University of Cyprus \\ and \\ Chris Charalambous \\ University of Cyprus
}

This version September 2000 


\begin{abstract}
The main purpose of this paper is the development and validation of a failure classification model for UK public industrial companies using current techniques: logit analysis and Neural Networks. Our dataset consists of 51 matched-pairs of failed and nonfailed UK public industrial firms over the period 1988-1997. Prediction models are developed for up to three years prior to the failure event. The models are validated using an out of sample period ex-ante test and the Lachenbruch technique. Our results indicate that a parsimonious model that includes three financial variables, a profitability, an operating cash-flow and a financial leverage variable can yield an overall correct classification accuracy of $83 \%$ one year prior to failure. In summary, our models can assist managers, shareholders, financial institutions, auditors and regulatory agents in the UK to forecast financial distress.
\end{abstract}




\section{Predicting Corporate Failure: Empirical Evidence for the UK}

\section{Introduction}

One of the most significant threats for many businesses today, despite their size and the nature of their operations, is insolvency. Extant evidence shows that in the past two decades business failures have occurred at higher rates than at any time since the early 1930's. It is also interesting to note that during the 1980 's certain sectors of the UK economy, such as small industrial businesses in depressed areas, experienced failure rates as high as 50\% over a five-year period (Rees, 1995).

The factors that lead businesses to failure vary. Many economists attribute this phenomenon to high interest rates, recession squeezed profits and heavy debt burdens. Furthermore, industry-specific characteristics, such as government regulation and the

nature of operations can contribute to a firm's financial distress. Studies of patterns of business failure in the UK, US, Canada and Australia (e.g. Star, 1990) found that small, private and newly-founded companies with ineffective control procedures and poor cash flow planning are more vulnerable to financial distress than large wellestablished public firms.

The economic cost of business failures is relatively large. Evidence shows that the market value of the distressed firms declines substantially (Warner, 1977). Hence, the suppliers of capital, investors and creditors, as well as management and employees are severely affected from business failures. The auditors will also face the threat of a potential lawsuit if they fail to provide early warning signals about failing firms through the issuance of qualified audit opinions (Boritz, 1991; Jones, 1987; Zavgren, 1983). 
Indeed, the need for reliable empirical models that predict corporate failure promptly and accurately is imperative, in order to enable the interested parties to take either preventive or corrective action. Although a substantial volume of failure prediction studies has been published since Beaver's pioneering work (1966), research interest has also continued in the '90s, especially in the US. However, in the UK, a great deal of research in this area was conducted in the '70s and '80s, with research interest declining dramatically in the '90s. One of the most prominent researchers who has developed failure prediction models using UK data is Taffler, whose contribution in this field has been undoubtedly valuable. The models developed by Taffler have performed well in terms of classification accuracy and they have become wellaccepted tools for practical financial analysis in the UK.

However, the majority of the UK corporate failure prediction studies was conducted in the 1980's using multiple discriminant analysis (MDA) and did not examine the usefulness of operating cash flow information despite the fact that there has been increasing interest in cash flow reporting in the UK in the past few years (FRS \#1, 1991, 1996; Charitou and Vafeas, 1998). Work by Mensah (1984) suggests that distress prediction models are fundamentally unstable, in that the coefficients of a model will vary according to the underlying health of the economy. This, along with results reported by other researchers (e.g. Moyer, 1977) suggest that the model derivation should be as close in time as possible to the period over which predictions are to be made (Keasy and Watson, 1991). Thus, there is a need for the construction of corporate insolvency prediction models using the latest possible financial data of UK companies. Moreover, although the MDA technique used in the majority of prior UK 
studies continues to be the focus of much academic research, questions were raised about the restrictive statistical requirements posed by the models (Ohlson, 1980). ${ }^{1}$

Thus, the main objective of this study is the development and testing of reliable failure classification models for UK public industrial firms. The present study differs from prior UK studies in the following respects. First, we examine the usefulness of operating cash flows in predicting corporate failure. Second, we methodologically refine prior UK studies by 1) using a more recent sample of failed and nonfailed firms (1988-97), 2) using logit analysis and Neural Networks (NNs) to develop the prediction models and 3) using an out of sample period ex ante test as well as the Lachenbruch jackknife method to validate the results.

Our data set consists of 51 matched-pairs of failed and nonfailed UK public industrial firms over the period 1988-97. Logistic regression analysis and neural networks are used to develop corporate insolvency prediction models for one, two and three years prior to the event. The models are validated using a future-dated holdout sample and logit models are also validated using the Lachenbruch jackknife technique. Our results indicate that a parsimonious model that includes three financial variables, a profitability, an operating cash flow and a financial leverage variable, can yield an overall correct classification accuracy of $82 \%$ one year prior to failure. Moreover, contrary to the findings of most prior studies, an operating cash flow variable was shown to add to the explanatory power of the models developed.

This study proceeds as follows. Section II motivates the study; the research design is presented in section III; the empirical results are presented and analysed in section IV; conclusions are presented in section V.

\footnotetext{
${ }^{1}$ The multiple discriminant approach (MDA) is based on the following assumptions that are frequently violated: a) the independent variables are multivariate normal and b) the covariance matrices of the two
} 


\section{Motivation for the study}

UK is considered a major worldwide economic market. The London Stock Exchange has a huge daily volume of transactions that competes against the other major international stock exchanges such as New York, NASDAQ, Tokyo and Toronto stock exchanges. Hence, researchers contend that the UK provides a financial environment 'ideal' for the successful development of statistical models for the assessment of company solvency and performance (Taffler, 1984). However, most researchers employed US data to extend the linear discriminant analysis approaches developed by Beaver (1966) and by Altman (1968) [see table 1]. ${ }^{2}$ These extensions include among others: i) the use of a more appropriate quadratic classifier (Altman et al., 1977), ii) the assignment of prior probability membership classes (Deakin, 1972), iii) the use of cash flow based models (Gentry et al., 1987), iv) the use of quarterly information (Baldwin and Glezen, 1992), v) the use of current cost information (Aly et al., 1992). Even though the aforementioned studies provided high classification accuracy, they were criticised because MDA models are based on certain assumptions that are frequently violated.

Since the multivariate discriminant analysis approach has certain limitations, Ohlson (1980) applied an alternative statistical method, logit analysis, in predicting corporate failure since this method avoids some of the argued limitations of the MDA approach. $^{3}$ Since then, logistic regression has been extensively used for the

\footnotetext{
groups (failed and nonfailed) are equivalent.

${ }^{2}$ For an in depth review of the corporate failure related literature see Keasey and Watson, 1991; Jones, 1987; Taffler, 1984 and Zavgren, 1983.

${ }^{3}$ Logistic regression has the following advantages over MDA models: (Ohlson, 1980, Mensah, 1984): a) No assumptions have to be made regarding prior probabilities of failure and the distribution of predictor variables, b) the use of such models permits an assessment of the significance of the individual independent variables included in the model, c) these models calculate the weight which each
} 
development of failure classification models (see table 1). Extensions to Ohlson's study include among others the following: i) the effect of industry-relative ratios on the likelihood of corporate failure (Platt and Platt, 1990), ii) distinguishing between firms in financial distress and failed firms (Gilbert et al, 1990), iii) development of industry specific models (Platt et al., 1994), iv) expanding the outcome space used to predict failure to include a third group of financially weak firms in an attempt to reduce the misclassification error (Johnsen and Melicher, 1994).

Neural Networks (NNs) is another technique that has been applied in the corporate insolvency prediction area mainly in the last two decades. NNs are computer systems that take their inspiration from known facts about how the brain works and they can be 'trained' to solve certain problems or identify specific patterns. Coats and Fant (1993) and Wilson and Sharda (1994) compared the results of multiple discriminant analysis against the neural network approach and their results suggested that the NNs approach is more effective than MDA in classifying distressed and nondistressed firms, whereas Boritz, Kennedy and Albuquerque (1995), after comparing two NNs techniques to MDA, probit and logit, as well as against Altman's and Ohlson's prediction models, found that the two NNs techniques did not provide superior classification rates. Similar results were also reported by Laitinen and Kankaanpaa (1999), who stated that '..., neural networks, is in its present form as effective as discriminant analysis was as early as thirty years ago'.

As far as the UK failure prediction studies are concerned, as already mentioned in the introduction, the great majority of them constructed their models using multiple discriminant analysis (MDA). Taffler constructed several failure classification models

coefficient contributes to the overall prediction of failure or nonfailure and produce a probability score, something which makes the results more accurate. 
using this technique $(1976,1977,1980,1982)$. Some UK researchers also examined the predictive ability of adjusted historic cost accounting ratios for either general price level changes (inflation) or for specific price changes (current cost accounting) (Ketz, 1978; Norton and Smith, 1979; Keasy and Watson, 1986 etc.). Nonetheless, their findings were conflicting. Moreover, notable is also the work by Keasy and Watson on small company failure $(1986,1987)$. Their latter study employed logit analysis for the model construction and along with Peel and Peel (1987), Storey et al. (1987) and Keasy and McGuiness (1990) are among the few researchers that have used probit and logit techniques in the UK. Another interesting UK study is the one by Molinero and Ezzamel (1991), who applied multidimensional scaling to corporate failure, a technique that produces graphical representations of the structures of the data, thus making it possible to acquire an intuitive understanding of its structure. Table 2 presents the main features of some representative UK insolvency studies.

However, all the aforementioned studies, regardless of the approached used, have one common impediment: they are not based on an economic theory in choosing the variables for distinguishing between failing and nonfailing firms. Instead, researchers selected financial ratios as predictor variables mainly because of their popularity and predictive success in previous research. However, this weakness is mitigated to some extent by validating the model with a holdout sample from a future time period. This approach was followed in designing the present study.

As it has already been discussed, one of the major motives of this study is the limited research on insolvency prediction conducted in the '90s in the UK and in particular the nonexistence research in this area that examines the usefulness of operating cash flow information. The following question, however, can justifiably be 
raised: Why cannot a model developed from US financial data be used to predict failure using UK company data? There exists evidence that a) there are significant financial reporting differences between the two countries (Nobes and Parker, 1999) and b) US and UK have also different insolvency codes (Franks et al., 1996). As far as UK research on corporate insolvency prediction is concerned, evidence shows that this research was undertaken mainly in the 1980 ' $\mathrm{s}^{4}$. Since the majority of UK insolvency studies was conducted in the 1980's, it can thus be argued that the models developed in these studies may not be applicable nowadays since various economic changes have occurred in the UK since then. This study employs the latest UK data set to develop and test insolvency classification models. In addition, since UK researchers employed mainly the MDA approach to develop their empirical models, a method that was shown to suffer from certain limitations, we employ two alternative approaches in the present study, i.e., logit analysis and NNs.

Furthermore, since organisations cannot survive without generating cash from their normal everyday operations, we develop several operating cash flow related ratios in order to evaluate their usefulness in predicting corporate failure ${ }^{5}$. Prior US studies provided some evidence that these variables add to the explanatory power of the insolvency prediction models developed (Gentry et al. 1987; Gilbert et al., 1990; Ward, 1994). In contrast, existing UK failure literature evidence reveals that operating cash flow variables have not been used in UK insolvency models despite the fact that there has been increasing interest in cash flow reporting in the UK in the past few years (FRS \#1, 1991, 1996; Charitou and Vafeas, 1998).

\footnotetext{
${ }^{4}$ See Taffler (1984) for a review of the failure related literature undertaken prior to the mid-80s.
} 


\section{Methodology}

In this section we discuss a) the data set, b) the selection of the predictor variables and c) the statistical models used.

\section{a) Data set}

The majority of corporate failure prediction studies defined failure legalistically, since this kind of definition possesses certain advantages (can be objectively dated, it provides an objective criterion that allows researchers to easily classify the population of firms being examined). This approach is also followed in this study, where the selection of sample failed firms was made according to the options available for companies as per the Insolvency Act of 1986. This act provides five courses of action for insolvent companies: administration, company voluntary arrangement (CVA), receivership, liquidation and dissolution. However, due to difficulties in finding annual financial statements for the companies that filed under the CVA and dissolution, the five insolvency options were limited to the three most usual ones (i.e. liquidation, administration and receivership). The failed firms were identified from 1) the Compustat (Global) database and 2) the UK insolvency credit database.

Our final data set consists of 51 failed firms that met the following criteria: 1) the company's shares must have been publicly traded, i.e. the company must have been a public limited one (plc) according to the UK Companies Act of 1985, 2) the company must have been classified as industrial. Utilities, banks and other financial institutions were excluded from the data set since firms in these industries are structurally different and their financial reporting practices generally preclude

\footnotetext{
${ }^{5}$ Net cash flow from operating activities differs from net income for three main reasons: "noncash" expenses, timing differences and "nonoperating" gains and losses.
} 
combining them with nonfinancial firms in models using financial ratios (Gilbert et al., 1990) and 3) sample firms must have had at least 3 years of data prior to their failure $^{6}$. Table 5 presents a list of all failed and their matched nonfailed firms. The year of failure and the standard industrial classification (SIC) of the failed firms is also presented.

The financial information needed for this study was collected from the following sources: a) Datastream, b) Compustat (Global), c) Worldscope European Disclosure and d) Silverplatter: UK Corporations. Information for failure dates was collected from the Wall Street Journal Index (Europe) and from the UK Insolvency database. After the sample of failed firms was obtained, a control sample of nonfailed firms was drawn. Moreover, consistent with the majority of prior insolvency prediction studies, the insolvent firms were matched with healthy firms by fiscal year, industry and asset size ${ }^{7}$.

\section{b. Selection of predictor variables}

Table 4 presents the major financial ratios that were found statistically significant in predicting failure in prior research. These ratios were also examined in this study. In order to identify the statistically significant ratios, univariate logistic

\footnotetext{
${ }^{6}$ It must be noted that the initial target of this research study was to predict insolvency for up to five years earlier, since many researchers have observed that failed companies have different characteristics for up to five years prior to their failure (Beaver, 1966; Molinero and Ezzamel, 1991). However, there were difficulties in finding an adequate number of failed companies in the databases available which had financial data for so many years prior to insolvency.

${ }^{7}$ Jones (1987) states the advantages of matching " Bankrupt firms are often disproportionately small and concentrated in certain failing industries. If nonbankrupt firms were drawn at random, there would probably be substantial differences between the two groups in terms of size and industry. The result is that the model attempting to discriminate between failing and healthy firms may actually be distinguishing between large and small firms, or between railroads and other industrials". A number of researchers, though, seems to disagree with the above. Foster (1986) and Taffler (1982) argue that matching failed and nonfailed firms by industry, size or financial year end eliminates the predictive power of these variables, possibly resulting in a restricted, rather than a general, model of company failure.
} 
regression was performed for each one of the forty-nine ratios ${ }^{8}$. Table 6 presents the financial ratios that were found to be statistically significant (at the $10 \%$ level) in univariate analysis. In addition, the forward logistic selection and backward elimination methods were applied and different combinations of the ratios were tested. The selection of the final set of ratios was based on the statistical significance of the estimated parameters, the sign of each variable's coefficient and the model's classification results.

\section{c. The logit model}

The logit model utilises the coefficients of the independent variables to predict the probability of occurrence of a dichotomous dependent variable. Specifically, the technique weights the independent variables and creates a score for each company in order to classify it as failed or healthy. The function considered in logistic regression is called the logistic function and can be written as follows:

$$
\mathrm{P}_{\mathrm{jt}}(\mathrm{Y}=1)=1 /\left(1+\mathrm{e}^{-\mathrm{z}}\right)=1 /\left\{1+\exp \left[-\left(\mathrm{b}_{0}+\mathrm{b}_{1} \mathrm{X}_{1}+\mathrm{b}_{2} \mathrm{X}_{2}+\ldots+\mathrm{b}_{\mathrm{n}} \mathrm{X}_{\mathrm{n}}\right)\right]\right\}
$$

where:

$\mathrm{P}_{\mathrm{jt}}(\mathrm{Y}=1)=$ Probability of failure $(1$ for failed companies and 0 otherwise) for entity $j$ at the end of year $t$; exp $=$ exponential function; $b_{1}, b_{2}, \ldots, b_{n}=$ slope coefficients; $X_{1}, X_{2}, \ldots, X_{n}=$ predictor variables.

\section{d. Neural Networks}

Neural Networks are inspired by neurobiological systems. Robert HechtNielsen, inventor of one of the earliest neurocomputers, defines a neural network as a computing system made up of a number of simple, highly interconnected processing

\footnotetext{
${ }^{8}$ Statistical analysis was performed with the SPSS (version 8.0) statistical package. Since we did not wish our prediction models to be sample depended, the cutoff point used for logistic regression was 0.5 .
} 
elements which process information by their dynamic state responses to external inputs.

Each processing element receives and combines input signals and transforms them into a single output signal. Each output signal, in turn, is sent (from its processing element) as an input signal to many other processing elements (and possibly back to itself). Signals are passed around the network via weighted interconnections (links) between processing elements. Network knowledge is stored both in the way the processing elements connect in order to transfer signals and in the nature and strength of the interconnections (Coats and Fant, 1993).

The concept of an artificial neural network has been around since the early 1940's (McCulloch and Pitts, 1943). In the mid-1980's, there was a revival of interest in NNs with the publication of the particularly influential Parallel Distributed Processing by Rumelhart, McClelland and their colleagues (1986, 1988). In the past several years, numerous models, articles, software packages, hardware and applications have been developed and it is widely held that NNs represent opportunities for enhancing the capabilities of systems that involve pattern recognition and classification (Boritz, Kennedy and Albuquerque, 1995).

NNs have been used successfully in many accounting and financial applications $^{9}$. Dutta and Shekhar (1988) and Surkan and Ying (1991) have applied NNs to bond ratings. White (1988) examined the efficient market hypothesis using a NN. Hansen et al. used a NN to distinguish between qualified and unqualified audit opinions and litigated and non-litigated firms.

\footnotetext{
${ }^{9}$ For a detailed discussion of NNs and their applications in the accounting field, see Trigueiros and Taffler, 1996.
} 
A major advantage of NNs is their ability to induce algorithms for recognising patterns. Unlike traditional models, the NNs approach is considered to be more robust in that it is not subject to restrictive statistical assumptions such as the linear relation and/or multivariate normality. As such it has an adaptive nature and has the ability of expressing non-linear relations (Suh and Kim, 1996). As pointed out by Hawley et al. (1990), the NN approach can be most effectively applied to such tasks as classification and clustering where problem-solving environments are unstructured with incomplete data.

However, NNs also present some drawbacks. First, they do not provide the contribution of each variable to the final classification (i.e. the variable's significance). Thus, it is impossible for an investigator to select the most significant predictor variables for the model development with the NNs approach. In addition, the investigator must decide upon the physical architecture of the network. This is often done by trial and error, varying the number of layers, the number of processing elements in each layer, the nature of the connection patterns etc. Moreover, the danger of over-parameterisation of the models is always present and finally, derived weights are not readily interpretable as with discriminant or logit analysis (Trigueiros and Taffler, 1996).

\section{Empirical results}

In this section we discuss a) descriptive statistics, b) univariate analysis, c) the multivariate logistic regression models, d) the validation of the logit models, e) the application of Altman's variables, f) neural networks results and g) comparison of the all results.

\section{a) Descriptive statistics}


A basic step for the analysis of the data is the identification of any significant differences between the two groups of companies (i.e. failed and nonfailed). Initially, this was accomplished through the calculation of the significant descriptive statistics for all financial ratios used in the study. In figure I we present the median of three representative statistically significant variables over the three-year period prior to the year of failure. ${ }^{10}$ First, the medians of all three variables differ between the two groups of firms. Second, the medians of the CFFOTL (cash flows from operations to total liabilities) and EBITTL (earnings to total liabilities) for the insolvent group present a decreasing trend as the year of failure approaches, whereas the medians of the healthy firms do not follow any specific pattern. This observation is consistent with our expectations (i.e., cash flow and profitability measures are negatively related with the probability of failure). Third, the median of the TLTA variable (total liabilities to total assets) presents an increasing trend as the year of failure approaches, whereas it remains relatively stable for the healthy firms. This observation is also in accordance with our expectations, i.e., that financial leverage is positively related to the probability of failure. ${ }^{11}$

\section{b) Univariate analysis}

The objective of the univariate logistic approach is to evaluate the predictive ability of each variable for one, two and three years prior to failure (Beaver, 1966). Table 6 presents the univariate results for the statistically significant ${ }^{12}$ variables one year prior to failure. Data for the period 1988-94 are used to test the variables.

\footnotetext{
${ }^{10}$ We have also observed the trend of the median and mean of all variables used in the study. The results are consistent with our expectations. These trends and the descriptive statistics of all variables are available upon request.

${ }^{11}$ Prior to testing the final multivariate regression models we also performed correlation analysis and multicollinearity tests (Variance inflation factors and pairwise correlations) [Dielman, 1996].
} 
Univariate results show that financial leverage, cash flow, liquidity, profitability and activity ratios can be used to predict failure. Several variables are shown to have at least $80 \%$ classification accuracy one year prior to failure. It should be noted that the financial leverage ratios provide the highest univariate classification accuracy. More specifically, the retained earnings to total assets ratio (REAT) achieves nearly $90 \%$ overall correct classification for the training sample for the first year prior to failure and it retains its strong classification accuracy in the other two years $(84.09 \%$ and $84.56 \%$ respectively). ${ }^{13}$ The findings for the financial leverage variables are not so surprising if one considers the fact that one of the main reasons that firms become insolvent is their inability to meet their heavy debt burdens. Relatively high overall classification accuracy is also provided by the profitability ratios for all three years prior to failure. The earnings before interest and taxes to total liabilities ratio (EBITTL) provides $85.42 \%$ overall correct classification rate for the first year prior to failure. Moreover, the operating cash flow variables (operating cash flows to current liabilities, CFFOLCT; and operating cash flows to total liabilities, CFFOTL) are both statistically significant and they achieve $67 \%$ and $69 \%$, respectively, overall correct classification. In summary, univariate analysis is a useful tool for the identification of the potential predictor variables that will ultimately be part of the multivariate $\operatorname{model}^{14}$.

c) The multivariate logistic regression model

\footnotetext{
${ }^{12}$ The level of significance used is $10 \%$.

${ }^{13}$ Results for two and three years prior to failure are consistent with our expectations and can be provided upon request.

${ }^{14}$ Nonetheless, the variables that are statistically significant in a univariate model will not necessarily enter in a multivariate model due to the following: a) multicollinearity problem and b) a variable may not add significantly to the overall predictive power of the model due to the presence of some other key variables, despite the fact that it provides high classification accuracy if included alone in the model.
} 
Besides the univariate (simple) logistic regression presented in the previous section, the selection of the significant predictor variables was also made using the forward selection and backward elimination methods. These two techniques are particularly useful since a) they select variables based on the Likelihood Ratio test, and, b) they avoid the multicollinearity problems that it is possible to arise with the inclusion of many variables. Finally, nearly all the possible combinations of the remaining variables were examined. Care, however, was taken for the variables' coefficients to be significant at the $10 \%$ level of significance, for the sign of each variable's coefficient to be in accordance with the one stated in the hypothesis and finally for the model to provide high classification results.

Panel A of table 7 presents multivariate logistic regression results one, two and three years prior to failure using data for the period 1988-94. Results show that the statistically significant predictor variables that entered the multivariate model are: cash flows from operations to total liabilities (CFFOTL), earnings before interest \& taxes to total liabilities (EBITTL) and total liabilities to total assets (TLAT). Interestingly, this is a parsimonious model that includes only three variables that represent the main categories of financial ratios, i.e. operating cash flow/liquidity, profitability and financial leverage ratios. Results also show that the debt ratio (TLAT) is positively associated with the probability of failure, whereas the profitability (EBITLT) and the operating cash flow (CFFOTL) variables are negatively related to the probability of failure. These results are consistent with our expectations. Moreover, consistent with univariate evidence, these results show that the debt ratio (TLAT) is the most significant variable. This variable alone provides $83.33 \%$ correct classification. The overall correct classification of the multivariate model for the first year prior to insolvency is $93.75 \%$. The type I and type II error rates are $8.33 \%$ and 
$4.17 \%$ respectively. ${ }^{15}$ However, in order to examine the model's external validity, the model should be tested against a holdout sample. This testing approach is discussed in the next section.

Multivariate results for the logit model two years prior to insolvency show that the model classifies correctly $84.09 \%$ of the firms. The type I and II error rates are $18.18 \%$ and $13.64 \%$, respectively. Finally, multivariate logit results three years prior to insolvency show that the model classifies correctly $69.44 \%$ of the firms. The type I and type II error rates are $33.33 \%$ and $27.88 \%$, respectively. In summary, consistent with prior empirical evidence, the highest correct classification rate is achieved in the first year prior to failure.

SPSS statistical package produces two statistics that are roughly equivalent in interpretation to the $\mathrm{R}^{2}$ in linear regression: Cox and Snell's $\mathrm{R}^{2}$ and Nagelkerke's $\mathrm{R}^{2}$. The former has the disadvantage that for discrete models (such as logistic regression), it may not achieve the maximum of one, even when the model predicts all the outcomes perfectly. Nagelkerke's $\mathrm{R}^{2}$ is an improvement of Cox and Snell's $\mathrm{R}^{2}$ that can attain a value of one when the model predicts the data perfectly. Thus, only Nagelkerke's $\mathrm{R}^{2}$ is reported (table 7 ) for all three models prior to failure. The interpretation is that the models explain about $88 \%, 49 \%$ and $40 \%$, for each of the three years, of the variation in the data. However, there is no formal test that can tell us if these percentages are sufficient or not.

A more widely used statistic for logistic regression models is the Likelihood Ratio test. This test checks if the null model (i.e. the model that only includes the constant term) fits the data as well as the fuller (final) model. In other words, it tests if

\footnotetext{
${ }^{15}$ Type I error is the misclassification of a failed firm as healthy and Type II error is the misclassification of a healthy firm as failed.
} 
the variables included in the final model are significant in explaining some of the variability in the data. Table 7 (Panel A) presents the Likelihood Ratio tests for the multivariate logistic regression models along with their respective significant levels. In all three models, the test is significant at the $1 \%$ level, indicating that the variables included can explain a significantly large proportion of the data variability.

Finally, to assess the concordance between observed and predicted, a Goodman-Kruskal coefficient of association was calculated (table 7). The result is 0.99 and 0.93 for the first two years, which are both very high and significantly different from zero at the $99 \%$ level. This coefficient, as expected, reduces to 0.68 in the third year.

\section{d) Validation of the Logistic Regression Model}

Validation tests examine the ability of classification models to predict failure among a new set of companies. Prior studies used various validation methods, among those 1) an out of sample period ex ante test (forecast test), and 2) the Lachenburch jackknife method. These methods are employed in the present study.

\section{Forecast validation test}

The external validity of the multivariate logit model discussed in the previous section is tested by using an out of sample period ex ante test. ${ }^{16}$ In testing the logit model that was developed using data for the period 1988-94, we use an equal sample of insolvent and healthy firms for the period 1995-97 (a total of 26 insolvent and 26 matched healthy firms). The overall correct classification results one, two and three

\footnotetext{
${ }^{16}$ As Jones (1987) comments, if a holdout sample is obtained from a later period, one can test for both overfitting and a violation of the stationarity assumption. The stationarity assumption implies that the relationship between the independent variables and the dependent variable will hold over time. Thus a number of researchers tested their models on a sample obtained from a later period (Platt and Platt, 1994; Mensah, 1984).
} 
years prior to failure are $80.95 \%, 73.81 \%$, and $72.92 \%$, respectively (table 9). Goodman-Kruskal $\gamma$ statistic also yields in high values $(0.90,0.79 \& 0.82)$, which are all significant at the $1 \%$ level, thus indicating a very good association between the observed and predicted. It is also interesting to note that in all years tested, the type I errors rates are much lower than the type II error rates. More specifically, the average type I error rate for all three years tested is about $15 \%$, whereas the average type II error rate is $32 \%$. This finding is very important since the cost of the two types of error rates differ. Altman et al. (1977) estimated type I error rates to be 35 times as costly as type II error rates.

In summary, the validation results of our study indicate that a parsimonious model with three variables, a profitability, a financial leverage and an operating cash flow/liquidity variable can provide reasonably good results in predicting financial distress in the UK. Another merit of this model is that its type I error rate is lower than the type II error rate.

\section{Lachenbruch jackknife method}

A statistical technique widely accepted for model validation is the Lachenbruch jackknife method. This method is particularly useful to researchers who deal with relatively small sample sizes, since the entire sample can be used to derive the parameters and a model is then constructed using n- 1 observations. The model is then used to predict the remaining observation. The process is repeated $\mathrm{n}$ times and the percentage misclassified is used to estimate the misclassification rate. According to Lachenbruch (1975) this method gives an almost unbiased estimate of the misclassification rate so that the statistical overfitting problem will be accounted for. However, jackknife method does not provide the test of external validity that a holdout sample offers (Jones, 1987). 
Thus, as mentioned above, the first step was to derive three failure prediction models (one for each year prior to insolvency) using the entire sample of both insolvent and healthy firms ${ }^{17}$. In order to be consistent with the multivariate logit model developed earlier, the same three variables (TLTA, EBITTL \& CFFOTL) were used. Panel $\mathrm{C}$ of table 7 presents the average classification results of this model one, two and three years prior to failure, which are $85.56 \%, 73.26 \%$ and $70 \%$ for each year, respectively ${ }^{18}$. The second step was the application of the jackknife validation method. Table 9 presents the validation (testing) results of this method. The correct predictions one, two and three years prior to failure are $82.22 \%, 72.09 \%$ and $70 \%$, respectively. These overall correct predictions are similar to those reported when we use the forecasting logistic method (see table 9).

\section{e. Application of Altman's variables}

The insolvency prediction model developed by Altman (1968) has been commonly applied in finance and accounting research. Furthermore, Altman's model has been used extensively by both academics and practitioners as a standard of comparison for subsequent insolvency classification studies (Wilson and Sharda, 1994; Coats and Fant, 1993). Thus, an attempt is also made in this study to examine whether Altman's significant variables can yield high classification results when they are applied to a more recent UK data set using the logistic regression technique.

Table 7 (Panel D) presents the training of Altman's variables. It is interesting to note that for the first year the model achieves the same classification results for the training sample as the logit model (Panel A). However, only one (MKVALDT) out of the five variables is significant at the $5 \%$ level. The overall results for the second year

\footnotetext{
${ }^{17} 90$ observations were used for the construction of the first model, 86 for the second and 80 for the third.
} 
are quite lower, as expected, but they are still satisfactory. Surprisingly, third year overall classification results are marginally higher than the second year's and they achieve the highest overall correct classification when compared with the two previous models (Panel A and Panel C). Type I error is lower than Type II in both years and only the leverage variable (REAT) is significant. Goodman-Kruskal $\gamma$ statistic yields in high values $(0.94,0.80 \& 0.81)$, which are all significant at the $1 \%$ level. The Likelihood Ratio test statistic indicates that the model significantly explains the variability in the training data set.

The external validity of Altman's model was tested by using the same futuredated holdout sample (1995-97) that was used for the validation of the logit model. Table 9 summarizes the results. Overall classification is high for the first year prior to failure $(82.50 \%)$, but declines substantially in the other two years $(62.50 \%$ and $68 \%)$. Thus, Altman's variables do not seem to perform that well when they are applied to a more recent UK data set, the main reason being the fact that these variables were selected by using an outdated US financial information.

\section{f) Neural Networks}

To validate and complement the prediction performance of the logit model, feedforward neural networks with conjugate gradient training algorithm were employed $^{19}$. A feedforward neural network consists of a set of input nodes that constitute the input layer, one or more hidden layers of neurons and an output layer of neurons. The network used in this study consists of three layers, the input layer, the hidden layer with a number of hidden neurons and the output layer with a single

\footnotetext{
${ }^{18}$ This model, for convenience, it is referred to as the Jackknife model.

${ }^{19}$ The NNs analysis was performed using the Matlab programming language.
} 
neuron. The hidden layer uses the hyperbolic tangent sigmoid activation function $\mathrm{f}_{\mathrm{h}}($.$) ,$ while the output layer uses the log-sigmoid activation function.

Panel B of table 7 presents the neural networks training (1988-94) classification results for one, two and three years prior to failure, while table 8 shows the final weights of the training phase of the feedforward networks. NNs provide higher overall classification results for the first and third year when compared to the logit model (95.83\% vs. $93.75 \%$ and $75 \%$ vs. $69.44 \%$ respectively), while the classification for the second year remains the same at $84.09 \%$. Interestingly, NNs also reduce significantly the type I errors for all three years prior to failure, providing no such error in the first year. Type II errors, however, increases for the first and second year, while it remains the same on the third year $(27.8 \%)$.

The external validity of the three NNs models is examined by means of the same future-dated data set (1995-97) as the one used to test the logit model. The resulting classification results are presented in table 9 . As expected, the overall correct classification results for the first two years are significantly lower to the respective ones of the training data set, but, surprisingly, this classification remains the same for the third year at $75 \%$. Moreover, in all three years the overall testing classification results of the NNs models are a bit higher than the ones of the logit models.

Another interesting observation concerns the type I errors: while NNs significantly reduce this error in the first year $(9.52 \%$ vs. $14.29 \%)$, they provide higher errors for the other two years when compared to the respective ones of the logit models. Type II error rates remain the same on the first year, while they significantly decrease on the second and third year.

g) Comparison of validation results 
This section compares the testing results (overall correct classification, type I and type II error rates) derived from the four alternative failure prediction models developed in this study. Table 9 summarises the results of these methods. As far as the overall correct classification is concerned, NNs were proved to be superior as they provided the highest prediction results in all three years prior to insolvency. Altman's model and jackknife validation model came second best for the first year, having approximately $1 \%$ difference with the NNs model. However, as far as the other two years are concerned, the logit model provided the second highest classification results, whereas Altman's variables performed the least well.

Since a type I error is more costly than a type II one, researchers tend to prefer prediction models that minimise type I errors. Table 9 shows that Altman's variables provide the lowest type I error rates for the first two years prior to failure (NNs also yield to approximately the same error rate as Altman's model on the first year). Nonetheless, as the type II error rates are very high (25\% and $60 \%$ respectively) this model proves to be quite inappropriate. Table 9 and figure II also show that the forecasting test (i.e. the so-called logit model) provides the lowest type I error rates (on average $15 \%$ in all three years tested), whereas the NNs models yield in slightly higher type I error rates (on average 17\%).

In summary, comparing the above results we conclude that the forecasting approach along with the NNs can be sound alternative failure prediction models for practical application purposes, since, despite the fact that they were tested on an out of sample period ex-ante test, they still led i) to high overall prediction rates and ii) to low type I error rates. 


\section{Summary and Conclusions}

The primary objective of this study was the development and testing of insolvency prediction models for UK public industrial firms. Even though several researchers attempted to develop failure prediction models, most of them used US data. In the UK the majority of failure prediction studies was conducted in the ' 70 s and '80s using discriminant analysis and ignored the role of operating cash flows in predicting failure. Therefore, the need for a failure prediction model development and validation using more recent UK financial data, including operating cash flow information, is indubitable.

Our data set consists of 51 matched-pairs of failed and nonfailed UK public industrial firms covering the period 1988-97. A parsimonious model including three financial variables (a profitability, a financial leverage and an operating cash flow) was developed based on a univariate and subsequently forward selection and backward elimination logistic regression analysis. The same three variables were also used for the development of alternative prediction models using feedforward neural networks. A forecasting test was employed to validate the models developed with the two methods (i.e. logit analysis and NNs). The logit models were also validated using the Lachenbruch jackknife method. Both approaches yielded in high prediction results one, two and three years prior to failure. However, the forecasting test results could be considered somewhat superior because even though this method is based on a futuredated sample test, its type I error rates were relatively low for both the logit and the NNs models. NNs achieved the highest overall classification results for all three years

prior to insolvency, with average classification of $78 \%$ (see figure II). The logit model, though, although it achieved a lower percentage of overall correct classification (average of $76 \%$ ), it resulted in slightly lower type I error rates (average of $16 \% \mathrm{vs}$. 
$17 \%$ of the NNs). Hence, we can deduce that both these models can be reliable alternatives for insolvency prediction in practical applications.

Moreover, in contrast to prior studies, our results indicate that operating cash flows play an important role in predicting failure. Furthermore, the potential application of the model developed by Altman (1968) was also examined, but the validation results were relatively low, indicating that this model may not be applicable to a more recent UK data set. In summary, our study extends prior studies in the following respects: First, we examine the usefulness of operating cash flows in predicting corporate failure. Second, we methodologically refine prior UK studies by a) using a more recent sample of failed firms (1988-97); b) using logistic regression and neural networks to develop the prediction models; c) using an out of sample period ex ante test, as well as the Lachenbruch jackknife method to validate the results. However, a limitation of this and all prior failure prediction studies is that the models are not based on any economic theory in choosing those factors that predict failure. Even though it is evident that the extant distressed prediction studies are mainly application driven, the development of a theoretical framework for failure prediction still remains. 


\section{References}

Accounting Standards Board, Financial Reporting Standard No. 1, Cash flow Statements, UK, September 1991 (revised 1996)

Altman E., "Financial Ratios, Discriminant Analysis and the Prediction of Corporate Bankruptcy", The Journal of Finance (September 1968), pp. 589-609.

Altman E., R. Halderman and P. Narayana, "Zeta Analysis", Journal of Banking and Finance (June 1977), pp. 29-54.

Aly I. M., H. A. Barlow and R. W. Jones, "The Usefulness of SFAS No.(Current Cost) Information in Discriminating Business Failure: An Empirical Study", Journal of Accounting, Auditing \& Finance (1992), pp. 217-229.

Baldwin J. and G. Glezen,"Bankruptcy Prediction Using Quarterly Financial Statement Data", Journal of Accounting, Auditing \& Finance (1992), pp.269290.

Beaver W., "Financial Ratios as Predictors of Failure", Empirical Research in Accounting, Supplement, Vol. 5, Journal of Accounting Research (1966), pp. 71-111.

Blum M., "Failing Company Discriminant Analysis", Journal of Accounting Research (Spring 1974), pp. 1-25.

Boritz J. E., The "Going Concern" Assumption: Accounting and Auditing Indications, 1991.

Boritz J. E., D. B. Kennedy and A. Albuquerque, "Predicting Corporate Failure Using a Neural Network Approach", Intelligent Systems in Accounting, Finance and Management (Vol.4 1995), pp. 95-111.

Casey C. and N. Bartczak, "Using Operating Cash Flow Data to Predict Financial Distress: Some Extensions", Journal of Accounting Research (Spring 1985), pp. 384-401.

Charitou A. and N. Vafeas, "The Association Between Operating Cash Flows and Dividend Changes: An Empirical Investigation”, Journal of Business Finance and Accounting (vol. 25 Jan/March 1998), pp. 225-249.

Charitou A. and E. Ketz, "Valuation of Earnings and Cash flows and their Components", Journal of Accounting, Auditing and Finance (vol. 5 1990), pp. 475-497.

Coats K. P. and L. F. Fant, "Recognising Financial Distress Patterns Using a Neural Network Tool”, Financial Management (1993), pp. 142-154.

Deakin E., "A Discriminant Analysis of Predictors of Business Failure", Journal of Accounting Research (Spring 1972), pp. 167-179.

Dielman T. E., Applied Regression for Business and Economics, $2^{\text {nd }}$ ed., Duxbury Press.

Dutta, S. and S. Shekhar, "Bond-Rating: A Non-Conservative Application of Neural Networks", Proceedings of the IEEE International Conference on Neural Networks, San Diego (1988), pp. 443-424.

Edmister R., "An Empirical Test of Financial Ratio Analysis for Small Business Failure Prediction”, Journal of Financial and Quantitative Analysis (March 1972), pp. 147-193.

El Hennaway R. and R. Morris, "The Significance of Base Year in Developing Factor Prediction Models, Journal of Business Finance and Accounting (vol. 10 1983), pp. 209-223. 
Franks R. J., K. G. Nyborg and W. N. Torous, "A Comparison of US, UK and German Insolvency Codes", Financial Management (Autumn 1996), pp. 86101.

Gentry J. A., P. Newbold and D. Whitford, "Classifying Bankrupt Firms with Funds Flow Components", Journal of Accounting Research (Spring 1985), pp. 146160.

Gentry J. A., P. Newbold and D. Whitford, "Funds Flow Components, Financial Ratios and Bankruptcy”, Journal of Business Finance (Winter 1987), pp. 595606.

Gilbert L., K. Menon and K. Schwartz, "Predicting Bankruptcy for Firms in Financial Distress", Journal of Business Finance (Spring 1990), pp. 161-171.

Hawley D. D., J. D. Johnson and D. Raina, “Artificial Neural Systems: A New Tool for Financial Decision-Making”, Financial Analysis Journal, (vol. 46 1990), pp. 63-72.

Jones F. L., "Current Techniques in Bankruptcy Prediction", Journal of Accounting Literature (1987), pp. 131-164.

Johnsen T. and R. W. Melicher, "Predicting Corporate Bankruptcy and Financial Distress: Information Value Added by Multinomial Logit Models", Journal of Economics and Business (1994), pp. 269-286.

Keasey K. and R. Watson, "Current Cost Accounting and the Prediction of Small Company Performance", Journal of Business Finance and Accounting (vol.13 Spring 1986), pp. 51-70.

Keasy K. and R. Watson, "The Prediction of Small Company Failure: Some Behavioural Evidence for the UK", Accounting and Business Research (vol. 65 1987a), pp. 49-58.

Keasy K. and R. Watson, "Non-Financial Symptoms and the Prediction of Small Company Failure: A Test of the Argenti Hypotheses", Journal of Business Finance and Accounting (vol. 14 1987b), pp. 335-354.

Keasey K. and R. Watson, "Financial Distress Prediction Models: A Review Of Their Usefulness", British Journal of Management (July 1991), pp. 89-102.

Keasy K. and P. McGuiness, "The Failure of UK Industrial Firms 1976-1984, Logistic Analysis and Entropy Measures", Journal of Business Finance and Accounting (vol. 17 1990), pp. 119- 136.

Ketz J., "The Effect of General Price Level Adjustments on the Predictability of Financial Ratios", Journal of Accounting Research (1978), pp. 273-284.

Laitinen E. K., "Financial Ratios and Different Failure Processes", Journal of Business Finance (September 1991), pp. 649-673.

Laitinen T. and M. Kankaanpaa, "Comparative analysis of failure prediction methods: the Finnish case", The European Accounting Review, (vol.8, 1999), pp. 67-92.

Lachenbruch P., 1975, Discriminant Analysis, New York: Hafner Press.

McCulloch W and W. Pitts, "A Logical Calculus of the Ideas Imminent in Nervous Activity", Bulletin of Mathematical Biophysics (vol. 58 1948), pp. 115-133.

Mensah Y., "An Examination of the Stationarity of Multivariate Bankruptcy Prediction Models: A Methodological Study", Journal of Accounting Research (Spring 1984), pp. 380-395.

Molinero C. M. and M. Ezzamel, "Multidimensional Scaling Applied to Corporate Failure", OMEGA International Journal of Management Science (vol. 19 1991), pp. 259-274.

Morris R., 1997, Early Warning Indicators of Corporate Failure, Ashgate. 
Moyer R. C., "Forecasting Financial Failure: A Re-Examination", Financial Management (vol.6 1977), pp.11-17.

Nobes C. and R. Parker, 1999, Comparative International Accounting, $5^{\text {th }}$ ed., Prentice-Hall International.

Norton C. and R. Smith, "A Comparison of General Price Level and Historical Cost Financial Statements in the Prediction of Bankruptcy", The Accounting Review (1979), pp. 72-87.

Ohlson J., "Financial Ratios and the Probabilistic Prediction of Bankruptcy", Journal of Accounting Research (Spring 1980), pp. 109-131.

Peel M. J. and D. A. Peel, "Some Further Empirical Evidence on Predicting Private Company Failure”, Accounting and Business Research (vol. 18 1987), pp. 5766.

Piesse J., and D. Wood, "Issues in Assessing MDA models of Corporate Failure: A Research Note", British Accounting Review (vol. 24 1992), pp. 33-42.

Platt H. D. and M. B. Platt, "Development of a Class of Stable Predictive Variables: The Case of Bankruptcy Prediction", Journal of Business Finance \& Accounting (Spring 1990), pp. 31-51.

Platt H. D., M. B. Platt and J. Pedersen, "Bankruptcy Discriminant with Real Variables", Journal of Business Finance \& Accounting (1994), pp. 491-510.

Scott J., "The Probability of Bankruptcy: A Comparison of Empirical Predictions and Theoretical Models", Journal of Banking and Finance (vol. 5 1981), pp. 317334.

Storey J., K. Keasey, R. Watson and P. Wynarczyk, 1987, The Performance of Small Firms, Croom-Helm, Bromley.

Rees, W., 1995. Financial Analysis, $2^{\text {nd }}$ ed., Prentice Hall.

Suh Y. H. and J. B. Kim, "Current Artificial Neural Network Models for Bankruptcy Prediction”, Journal of Accounting \& Business Research (vol. 4 1996), pp. 81101.

Taffler R. J., "Forecasting Company Failure in the UK Using Discriminant Analysis and Financial Ratio Data", Journal of Royal Statistical Society, (vol. 145 1982), pp. 342-358.

Taffler R. J., "The Assessment of Company Solvency and Performance Using a Statistical Model", Accounting and Business Research (Autumn, 1983), pp. 295-308.

Taffler R. J., "Empirical Models for the Monitoring of UK Corporations", Journal of Banking and Finance (vol. 8 1984), pp. 199-227.

Trigeiros D. and R. Taffler, "Neural Networks and Empirical Research in Accounting", Accounting and Business Research (vol. 26, 1996), pp. 347-355.

Ward T., "An Empirical Study of the Incremental Predictive Ability of Beaver's Naive Operating Flow Measure Using Four-State Ordinals Models of Financial Distress", Journal of Business Finance (June 1994), pp. 547-559.

Ward T., "Cash Flow Information and the Prediction of Financially Distressed Mining, Oil and Gas Firms: A Comparative Study", Journal of Applied Business Research (Summer 1994), pp. 78-85.

Warner J., "Bankruptcy Costs: Some Evidence", The Journal of Finance (1977), pp. 337-347.

Wilson R. L. and R. Sharda, "Bankruptcy Prediction Using Neural Networks", Decision Support Systems (1994) pp. 545-557. 
Zavgren C., "The Prediction of Corporate Failure: The State of the Art", Journal of Accounting Literature (vol. 2 1983), pp. 1-38. 